\title{
Article \\ Foreign Language Effect on Decision-Making when Compared to Native and Second language
}

\author{
Pratibha Ahirwal ${ }^{1}$ (1), Mahak Kothari ${ }^{2}$ and Veeky Baths ${ }^{3}$ \\ 1 Cognitive Neuroscience Lab, BITS Pilani K K Birla Goa Campus Goa, India; pratibhaahirwal66@gmail.com \\ 2 Cognitive Neuroscience Lab, Dept. of Computer Science \& Information Systems, BITS Pilani K K Birla Goa \\ Campus Goa, India; f20180232@goa.bits-pilani.ac.in \\ 3 Cognitive Neuroscience Lab, Dept. of Biological Sciences, BITS Pilani K K Birla Goa Campus Goa, India; \\ veeky@goa.bits-pilani.ac.in \\ * Correspondence: veeky@goa.bits-pilani.ac.in
}

check for updates

Citation: Ahirwal, P.; Kothari, M.; Baths, V. Title. Preprints 2021, 1, 0. https://doi.org/

Received:

Accepted:

Published:

Publisher's Note: MDPI stays neutral with regard to jurisdictional claims in published maps and institutional affiliations.

\begin{abstract}
Decision-making is a complex process of selecting an option from the given choices by analyzing the background information like risk, loss, and gain within the alternative options presented. It has been observed in earlier studies that people are prompt to make less rational decisions when choices are given in a language less known to them. Therefore, to understand the effect of languages on decision-making, we have questioned native Hindi speakers in French and English. French being the foreign language, and English as their second language. Thus, this effect of a non-native language brings to light the important role that the native language plays routinely in judgment and decision-making. In this paper, we developed a Neuropsychological assessment to decipher the effects on decision-making between choices when given in foreign language and second language in comparison with the native language of an individual, which is termed as foreign language effect(Fle). We have explored various possible situations to understand the foreign language effect(Fle) in decision-making and does this change translates when the decision is to be made in the second language. Our study concludes that the Foreign language is least affected by the intuitive biases, followed by the second language, and the native language is most affected by it.
\end{abstract}

Keywords: Foreign Language effect; decision-making; native language; second language; risk-taking

\section{Introduction}

Foreign language effects (FLe) have gotten a lot of attention in the field of judgement and decision-making psychology [12]. According to an intriguing piece of research, when people analyse decisions in a less familiar language, it appears to lead to additional rational and fewer emotional outcomes [11]. Especially, current researchers have suggested that presenting situations and choices [13] in a foreign language helps individuals make better choices. These findings reveal that reading dilemmas in a very foreign language scale back each harm-rejection and outcome-maximization inclinations [4]. Foreign language effect (Fle) is determined as the possibility of distinction in curating decisions once the things square measure presented in a very language aside from the linguistic communication [18].

One of the most essential aspects of Fle's decision-making research is risk management [5]. This would show how the framing effect causes emotional bias towards a particular option in one language against the other. This also shows that even in the risk management process, decision makers can be swayed to make a particular judgement in a particular language [20]. Presenting the message in the recipient's second language may help to alleviate the emotional anguish that stakeholders often face during an organisational crisis [9]. The usage of a foreign language can have a significant impact on one's decision-making process [2], [12].

As research [8] show, the amount to which language effects a bilingual's brain processes is not only related to the perceived various emotional intensity of the given message. Different research groups apply different criteria to assign participants to different monolingual or bilingual groups and to determine the quantitative assessment indicating the extent of bilingualism [1]. An apparent solution to this method of describing an individual's 
bilingualism is to administer language tests in both languages and formulate a score that captures both the exact and relative proficiency levels of each [14].

The language that is native to the topic is spoken as native language/ mother tongue and also the one noninheritable later in life is spoken as foreign language. There are two major instruments that have been accustomed to assess bilingualism - the Language Experience and Proficiency Questionnaire (LEAP-Q [17], [10]) and also the Language History Questionnaire (LHQ 2.0) [15].The LEAP-Q includes questions about the participants' language dominance, language proficiency, preference for each language, age of language acquisition, as well as present and previous exposure to their native tongues in a variety of circumstances. To establish the internal validity, [17]tested the LEAP-Q with 52 heterogeneous bilinguals and analyzed the responses by using factor analysis with orthogonal rotations. The results revealed that levels of language proficiency, degrees of language use and exposure, age of second language acquisition, and length of the second language formal education best explained these individuals' self-ratings of bilingual and monolingual experience [6].

We have used modified versions of this questionnaire to fit into Indian language scenarios and focused our study on three languages. Since rustic with various cultural background individuals includes a type of native languages, they often have English as their second language because it is instructed in most of the institutions [7]. In the following study, we devised a neuropsychological examination to determine the impact on decision-making when choices are presented in a foreign language or a second language rather than an individual's native language, a phenomenon known as the foreign language effect (Fle). We looked at a variety of scenarios to see how the foreign language effect (Fle) affects decision-making and how this changes when the decision is made in a second language.

\section{Materials and Methods}

\subsection{Participants:}

Our experiment consisted of 150 students of BITS, Pilani, India, out of which 90 are males, and 60 are females. All of them have Hindi as their native language, English as their second language, and French as the foreign language. Their mean age was 22.8, with a standard deviation of 1.3. The mean age at which they started learning French was 14, with a standard deviation of 2.2. The average English language proficiency was 8 out of 10 with std 0.7 , the average Hindi language proficiency was 9 out of 10 with std 0.4 , and the average French language proficiency was 6 out of 10 with std 0.4. Most of the students learned french in their high school as an optional subject, while English was the primary mode of education.

\subsection{General procedure:}

We presented a questionnaire to these students, which consisted of two parts. The first part was designed to collect socio-demographic and linguistic information of these students like their age, mental illness (if any), where did they learn these languages, proficiency in each of these languages. In the second part, these 150 students were divided into three equal groups. Each group was randomly assigned the questions and the choices in one of the three languages. The questions were designed in such a way to understand the effect of the foreign, native, and second language on the following problems: Asian Disease problem, Financial Crisis problem [16], Discount problem, and Ticket/Money Lost problem. Questions associated with each of these problems is mentioned in Table 1.

\subsection{Framing effect in decision-making:}

Both the Asian Disease problem and the Financial Crisis problem have two questions associated with it, trying to understand the framing effect of these questions in each language. The framing effect is the psychological phenomenon that determines the effect on decision-making that is influenced by the way in which the task and the options have 


\begin{tabular}{|c|c|c|}
\hline QNo. & Problem & Question \\
\hline 1 & $\begin{array}{l}\text { Asian Disease } \\
\text { (Gain Version) }\end{array}$ & $\begin{array}{l}\text { Recently, a dangerous new disease has been going } \\
\text { around. Without medicine, } 600,000 \text { people will die } \\
\text { from it. In order to save these people, two types of } \\
\text { medicine are being made.If you choose Medicine A, } \\
200,000 \text { people will be saved. If you choose Medicine } \\
\text { B, there is a } 33.3 \% \text { chance that } 600,000 \text { people will be } \\
\text { saved and a } 66.6 \% \text { chance that no one will be saved. } \\
\text { Which medicine do you choose? }\end{array}$ \\
\hline 2 & $\begin{array}{l}\text { Asian Disease } \\
\text { (Loss Version) }\end{array}$ & $\begin{array}{l}\text { Recently, a dangerous new disease has been going } \\
\text { around. Without medicine, } 600,000 \text { people will die } \\
\text { from it. In order to save these people, two types of } \\
\text { medicine are being made.If you choose Medicine A, } \\
400,000 \text { people will die. If you choose Medicine B, } \\
\text { there is a } 66.6 \% \text { chance that } 600,000 \text { people will die and } \\
\text { a } 33.3 \% \text { chance that no one will die. Which medicine } \\
\text { do you choose? }\end{array}$ \\
\hline 3 & $\begin{array}{ll}\text { Financial } & \text { Crisis } \\
\text { problem } & \text { (Gain } \\
\text { Version) } & \end{array}$ & $\begin{array}{l}\text { If you choose Action A, } 200,000 \text { euros will be saved. } \\
\text { If you choose Action B, there is a } 33.3 \% \text { chance that } \\
600,000 \text { euros will be saved and a } 66.6 \% \text { chance that no } \\
\text { money will be saved. Which action do you choose? }\end{array}$ \\
\hline 4 & $\begin{array}{ll}\text { Financial } & \text { Crisis } \\
\text { problem } & \text { (Loss } \\
\text { Version) } & \end{array}$ & $\begin{array}{l}\text { If you choose Action A, } 400,000 \text { euros will be lost. If } \\
\text { you choose Action B, there is a } 33.3 \% \text { chance that no } \\
\text { money will be lost and a } 66.6 \% \text { chance that } 600,000 \\
\text { euros will be lost. Which action do you choose? }\end{array}$ \\
\hline 5 & $\begin{array}{l}\text { Discount problem } \\
\text { (on } 15 \text { euros) }\end{array}$ & $\begin{array}{l}\text { Imagine that you want to buy a jacket for } 125 \text { euros } \\
\text { and a calculator for } 15 \text { euros. The salesman tells you } \\
\text { that the calculator you want to buy is on offer for } 10 \\
\text { euros at their other shop, located } 20 \text { min drive away. } \\
\text { Would you make the trip to the other shop? }\end{array}$ \\
\hline 6 & $\begin{array}{l}\text { Discount problem } \\
\text { (on } 125 \text { euros) }\end{array}$ & $\begin{array}{l}\text { Imagine that you want to buy a jacket for } 15 \text { euros and } \\
\text { a calculator for } 125 \text { euros. The salesman tells you that } \\
\text { the calculator you want to buy is on offer for } 120 \text { euros } \\
\text { at their other shop, located } 20 \text { min drive away. Would } \\
\text { you make the trip to the other shop? }\end{array}$ \\
\hline 7 & $\begin{array}{l}\text { Ticket Lost prob- } \\
\text { lem }\end{array}$ & $\begin{array}{l}\text { A woman has bought two tickets to go to the theatre []. } \\
\text { Each ticket costs } 80 \text { euros. When she arrives at the } \\
\text { theatre, she opens her bag and discovers that she has } \\
\text { lost the tickets. Do you think she will buy the tickets } \\
\text { to enter the theatre? }\end{array}$ \\
\hline 8 & $\begin{array}{l}\text { Money lost prob- } \\
\text { lem }\end{array}$ & $\begin{array}{l}\text { A woman goes to the theatre and wants to buy two } \\
\text { tickets that cost } 80 \text { euros each. She arrives at the theatre, } \\
\text { opens her bag, and discovers that she has lost the } 160 \\
\text { euros with which she was going to buy the tickets. She } \\
\text { could use her credit card. Do you think she will buy } \\
\text { the tickets to enter the theatre? }\end{array}$ \\
\hline
\end{tabular}

Table 1: The problem scenarios and their versions

been framed. The same information, when framed in a different manner, can provide us with varied answers. Both of these problems were designed in such a way that the expected value of both the outcomes in each question is the same. Earlier studies [12] have shown that participants are sensitive to the expected value and are likely to choose an option with a higher expected value of gain or a positive outcome. Therefore, to prevent participants from choosing an option based on expected value, the options in these questions have the 
same expected value. These questions have two options, one with low risk and low return, and the other with high risk and a greater return.

\subsection{Psychological accounting:}

Participants were presented with the Discount problem [19] and the Ticket/Money Lost problem to understand the psychological accounting of outcomes. Psychological accounting is the phenomenon that is used to explain how humans decode, categorize and evaluate economic outcomes. In the Discount problem, there is the same monetary gain in both the questions. But why people favored one situation over the other. Similarly, in the Ticket/Money lost problem, although the woman has lost the same amount of money in both the questions, people prefer to re-buy the tickets in one situation and not in another.

\section{Results}

\subsection{Asian Disease Problem:}

Ideally, since both options have an equal expected value, the number of people choosing option A should be nearly the same as the number of people choosing option B. But as shown in Fig. 1, this number varies based on the language. In the Gain version, people who were questioned in French, the foreign language, $40 \%$ of them chose option A, whereas people who were questioned in Hindi, the native language, $70 \%$ of them chose option A. People who were questioned in English, the second language, $62 \%$ chose option A. In the Loss version, $46 \%$ of the participants who answered in French chose option A, $40 \%$ of who answered in Hindi chose option A, whereas $42 \%$ of them who answered in English chose option A. It is evident from the data that when given a choice in a foreign language, people are equally inclined to take a risk, whether it is a gain or a loose situation $\left(\chi^{2}(1, N=50)=3.6, p>.05\right)$. In the Native language, we can clearly see the framing effect $\left(\chi^{2}(1, N=50)=5.3, p<.03\right)$. The effect of a second language on risk-taking decisions is more similar to a native language $\left(\chi^{2}(1, N=50)=4.2, p<.05\right)$, as we can see the disparity in taking risks between the gain and the loss situation.

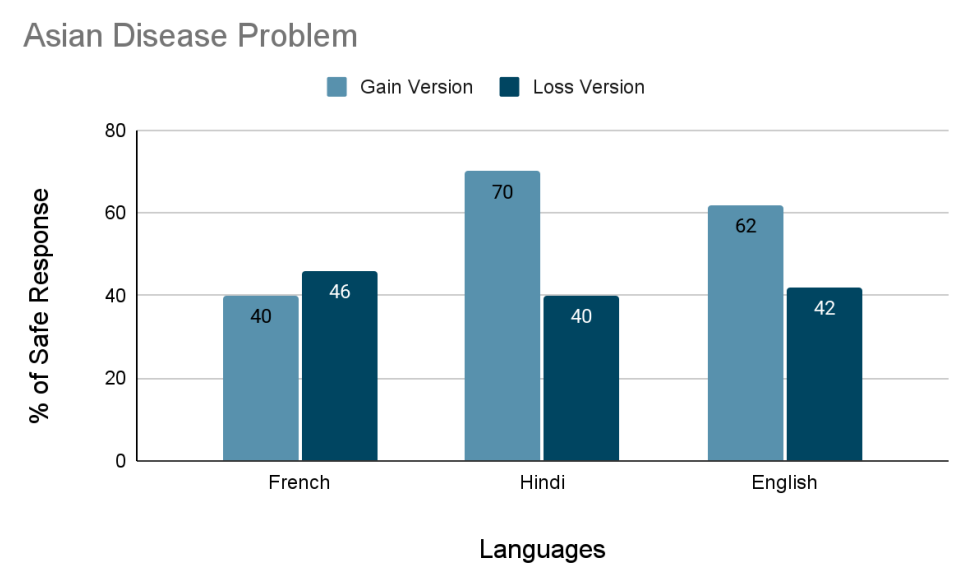

Figure 1. Percentage of safe responses for different versions of the "Asian Disease Problem" within the three language groups.

\subsection{Financial Crisis Problem}

In the Gain version of the problem, $78 \%$ of the participants chose option A when questioned in their native language, $66 \%$ of participants selected option A when questioned in the second language, and $58 \%$ of the participants who were questioned in the foreign language chose option A. In the loss version of the problem, option A was chosen by $30 \%$ of participants who were questioned in their native language, $44 \%$ of participants who were questioned in their second language, and $46 \%$ of the participants who were questioned in the foreign language as seen in Fig. 2. Here we see that in the native language, participants' 
choice about similar problems in terms of outcomes is influenced by the way the problems were framed. When the options were provided in terms of losses, participants tended to prefer more risk (or be less conservative) than when they were presented in terms of winnings in their native language $\left(\chi^{2}(1, N=50)=12, p<.01\right)$. This framing effect was seen to be reduced when the problem was presented in the second language $\left(\chi^{2}(1, N=\right.$ $50)=7.2, p<.01)$ and was least in the foreign language $\left(\chi^{2}(1, N=50)=4.6, p<.04\right)$.

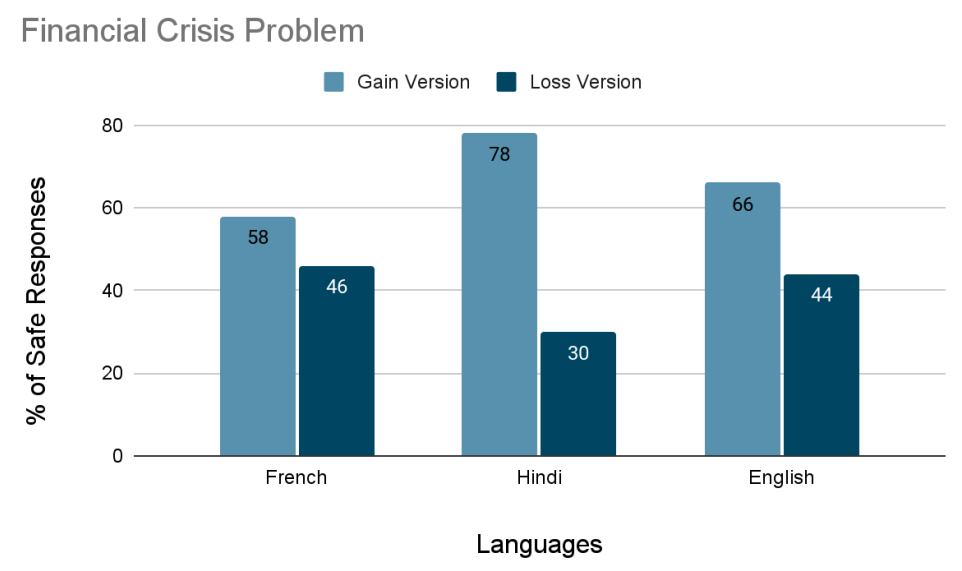

Figure 2. Percentage of safe responses for different versions of the "Financial Crisis problem" within the three language groups.

\subsection{Discount problem:}

From Fig. 3, it can be seen that, despite the equal monetary benefits in both the questions, people are more inclined to drive away in the first case when a discount of 5 euros is made on 15 euros, as compared to the second case when a discount of 5 euros is given on 125 euros. A possible explanation of this is that people generally see this problem in terms of percentage gain. When 5 euros are saved when buying something for 15 euros, people see it more profitable than 5 euro discount on 125 euros. Although they are saving an equal amount in both situations and spending the same time to save them, they generally prefer to save in the first situation. Although in all three languages, people preferred to take a discount on 15 euros, then on 125 euros, the difference in the percentage of people willing to take a discount on 15 euros and on 125 euros is largest in the native language $\left(\chi^{2}(1, N=50)=8.6, p<.01\right)$, followed by the second language $\left(\chi^{2}(1, N=\right.$ $50)=6.6, p<.02)$, and is least in the foreign language $\left(\chi^{2}(1, N=50)=3.4, p>.05\right)$. This shows the framing effect in the native language.

\subsection{Ticket/Money lost problem:}

From Fig. 4, It is evident that in all the three language, native $\left(\chi^{2}(1, N=50)=4.1, p<\right.$ $.05)$, foreign $\left(\chi^{2}(1, N=50)=4.3, p<.04\right)$, and second language $\left(\chi^{2}(1, N=50)=4.1, p<\right.$ $.05)$, people preferred to re-buy the tickets when money was lost and were reluctant to re-buy when tickets were lost. A plausible interpretation of these observations as given by [3] is that, whilst in the first scenario, the final cost for theatre tickets is psychologically accounted to be 320 euros and regarded as excessively expensive, this is not the case in the second scenario, and the loss of the 160 euros is not accounted for as part of the ticket price. From the chi-square test, it is apparent that no FLe is shown in this problem.

\section{Conclusions}

To summarise, we investigated the effect of foreign, second, and native languages on decision-making tasks. Our results clearly state the impact of these languages on different problem scenarios. The framing effect played a crucial role while making a decision in the native language. Responses of the people who were questioned in the foreign language 


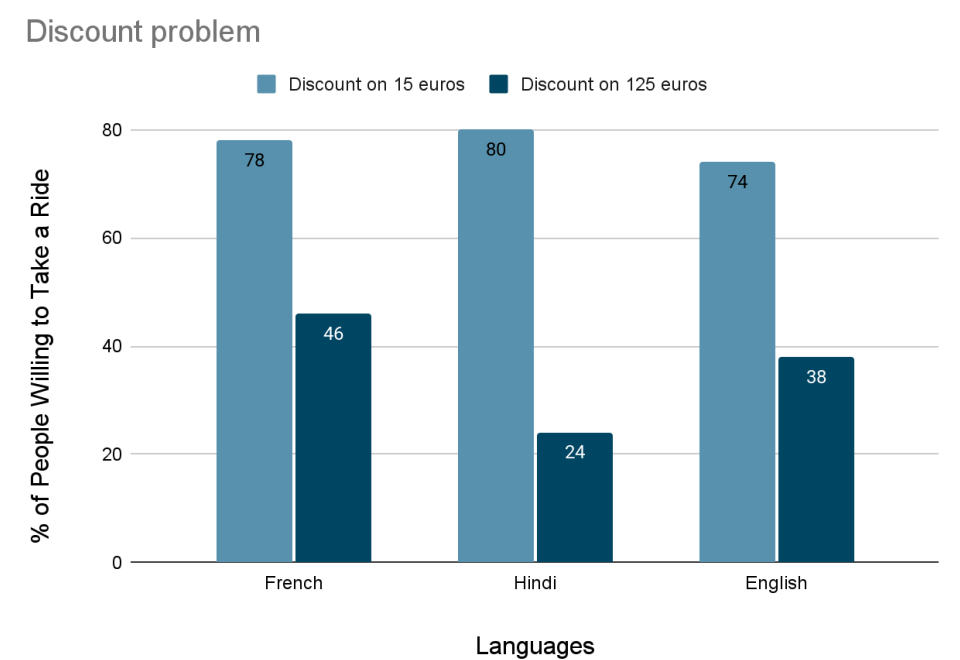

Figure 3. Percentage of responses for different versions of the "Discount problem" within the three language groups.

Ticket/Money Lost problem

Ticket Lost $\square$ Money Lost

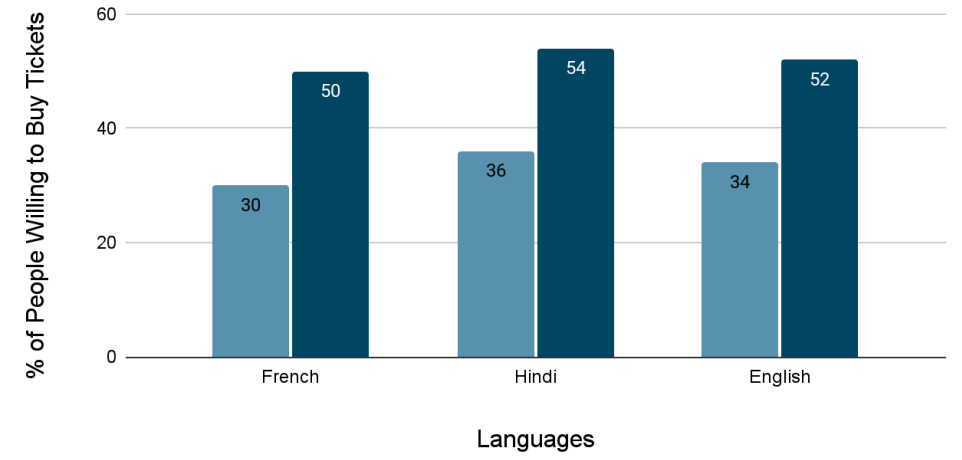

Figure 4. Percentage of responses for different versions of the "Ticket/Money Lost problem" within the three language groups.

were less affected by the intuitive bias. Apart from these two languages, our study has also revealed the effect of the second language in making decisions. Responses of people who were questioned in their second language were intermediate between the foreign language and the native language. They were not heavily influenced by the framing effect but were not completely free from it. Our experiments bolster the previous findings on FLe and initiate a new topic of discussion, i.e., the effect of the second language on decision-making.

Author Contributions: PA prepared the survey questions, helped with data analysis and manuscript preparation. MK helped in taking survey, data analysis and manuscript preparation. VB supervised the study and helped in manuscript creation.

Funding: This research received no external funding

Institutional Review Board Statement: Not applicable

Informed Consent Statement: Informed consent was obtained from all subjects involved in the study. Written informed consent has been obtained from the patient(s) to publish this paper

Data Availability Statement: The data collected in this study are available from the corresponding author upon request. 


\section{References}

1. Anderson, J. A. E., Mak, L., Keyvani Chahi, A., \& Bialystok, E. (2018). The language and social background questionnaire: Assessing degree of bilingualism in a diverse population. Behav Res Methods, 50(1), 250-263.

2. Cipolletti Perez, H., McFarlane, S., \& Weissglass, C. (2015). The Moral Foreign-Language Effect. Philosophical Psychology, 29, 1-18.

3. Costa, A., Foucart, A., Arnon, I., Aparici, M., \& Apesteguia, J. (2014). "Piensa" twice: on the foreign language effect in decision making. Cognition, 130(2), 236-254. https://doi.org/10.1016/j.cognition.2

4. Doerflinger, J. T., \& Gollwitzer, P. M. (2020). Emotion emphasis effects in moral judgment are moderated by mindsets. Motivation and Emotion, 44(6), 880-896.

5. Gigerenzer, G., \& Goldstein, D. G. (1996). Reasoning the fast and frugal way: models of bounded rationality. Psychol Rev, 103(4), 650-669.

6. Hartshorne, J. K., Tenenbaum, J. B., \& Pinker, S. (2018). A critical period for second language acquisition: Evidence from 2/3 million English speakers. Cognition, 177, 263-277.

7. Jenkins, J. (2014). Global Englishes third edition. A resource book for students.

8. Hayakawa, S., Lau, B. K. Y., Holtzmann, S., Costa, A., \& Keysar, B. (2019). On the reliability of the foreign language effect on risk-taking. Q J Exp Psychol (Hove), 72(1), 29-40.

9. Jin, Y., Pang, A., \& Cameron, G. (2010). The role of emotions in crisis responses: Inaugural test of the integrated crisis mapping (ICM) model. Corporate Communications: An International Journal, 15, 428-452.

10. Kaushanskaya, M., Blumenfeld, H., \& Marian, V. (2019). The Language Experience and Proficiency Questionnaire (LEAP-Q): Ten years later. Bilingualism: Language and Cognition, 23, 1-6.

11. Kensinger, E. A. (2009). Remembering the Details: Effects of Emotion. Emot Rev, 1(2), 99-113.

12. Keysar, B., Hayakawa, S. L., \& An, S. G. (2012). The foreign-language effect: thinking in a foreign tongue reduces decision biases. Psychological Science, 23, 661-668.

13. Kroll, J. F., \& Dussias, P. E. (2017). The Benefits of Multilingualism to the Personal and Professional Development of Residents of The US. Foreign Lang Ann, 50(2), 248-259. https://doi.org/10.1111/flan.12271

14. Lehtonen, M., Soveri, A., Laine, A., Jarvenpaa, J., de Bruin, A., \& Antfolk, J. (2018). Is bilingualism associated with enhanced executive functioning in adults? A meta-analytic review. Psychol Bull, 144(4), 394-425.

15. Li, P., Sepanski, S., \& Zhao, X. (2006). Language history questionnaire: A web-based interface for bilingual research. Behav Res Methods, 38(2), 202-210.

16. Liberman, V., Samuels, S. M., \& Ross, L. (2004). The name of the game: Predictive power of reputations versus situational labels in determining prisoner's dilemma game move. Personality and Social Psychology Bulletin, 30(9), 1175-1185.

17. Marian, V., Blumenfeld, H. K., \& Kaushanskaya, M. (2007). The Language Experience and Proficiency Questionnaire (LEAP-Q): Assessing Language Profiles in Bilinguals and Multilinguals. Journal of Speech, Language, and Hearing Research, 50(4), 940-967.

18. Muda, R., Niszczota, P., Bialek, M., \& Conway, P. (2018). Reading dilemmas in a foreign language reduces both deontological and utilitarian response tendencies. J Exp Psychol Learn Mem Cogn, 44(2), 321-326.

19. Tversky, A., \& Kahneman, D. (1981). The framing of decisions and the psychology of choice. Science, 211(4481), 453-458.

20. Wurth, K. M., Reiter-Theil, S., Langewitz, W., \& Schuster, S. (2018). "Getting by" in a Swiss Tertiary Hospital: the Inconspicuous Complexity of Decision-making Around Patients' Limited Language Proficiency. J Gen Intern Med, 33(11), 1885-1891. 
